\title{
DEVELOPING EMPLOYEES' WORK-LIFE BALANCE STRATEGIES TO IMPROVE INDIVIDUAL HEALTH AND WELLBEING BALANCE
}

\author{
Ganesan Shanmugavelu ${ }^{1}, \mathbf{P h D}$ \\ Senior Lecturer, Institute of Teacher Education Ipoh Campus, Malaysia
}

\author{
Amuta Arumugam ${ }^{2}$ \\ Masters' Student, Universiti Utara Malaysia
}

Article DOI: https://doi.org/10.36713/epra5973

\begin{abstract}
The aim of this study is to discuss employees' work-life balance strategies to improve individual health and wellbeing balance. A healthy balance between work-life and home-life is incredibly important and something everyone should strive to achieve. However, it is not uncommon for employees to find their personal life, suffering as they struggle manipulate family, friends and other commitments with busy schedules. The finding determines that employees are desiring more control over their work patterns and an overall healthier work-life balance. The main aim of this case study is to explore the work-life balance that utilize to improve the employee's performance organization. This study also integrated the work-life balance effectiveness, the importance of a supportive work environment, employee commitment and motivation. Also emphasize, employee wellbeing and productivity, employee job satisfaction and quality work life, organizational culture change, and low utilization of the job sharing. The finding of work-life balance could help improve organizational culture and employee overall performance. In despite, may contribute a significant social change by preparing employees for success while simultaneously positioning individuals to attain the optimum balance between work and life responsibilities. Essentially, to keep pace with workplace trends, human resource professionals seek options to positively impact the bottom line of their companies, improve employee morale and retain employees with valuable company knowledge. Finally, the results perspective that human resource professionals can assist their companies to capitalize on these factors by using work-life balance initiatives to gain a competitive advantage in the effectiveness of work-life practices.
\end{abstract}

KEYWORDS : Workplace, Personal health, Stress, Strategic choices, Attitudes, Organization, Work-life balance

\section{INTRODUCTION}

Generally, well-being and work-life balance for employees can improve their overall health, and also help to improve their morale, motivation and general job satisfaction, leading to improved performance in the workplace. This study illustrates how a healthy work-life balance requires managing our professional and personal life in sustainable ways that keep energy flowing, minds and bodies healthy and whole selves happy. Meaning giving due attention to all of the things that enrich and satisfy peoples, including work and career, health and fitness, family 


\section{SJIF Impact Factor: 7.001| ISI I.F.Value:1.241| Journal DOI: 10.36713/epra2016 \\ ISSN: 2455-7838(Online) \\ EPRA International Journal of Research and Development (IJRD) \\ - Peer Reviewed Journal}

and relationships, spirituality, community service, hobbies and passions, intellectual stimulation, rest and recreation. Uncertainty an employee spends a majority of their time working and feels like they are neglecting the other areas of their lives, they often experience frustration, burnout, and unhappiness. Meaning when organizations promote good work-life balance, employees are less likely to experience stress and more likely to have a more positive outlook on their professional and personal lives overall. Work-life balance as a crucial factor while job hunting, a good work-life balance can fuel employees with better health, greater loyalty, commitment, engagement and increased productivity. Hence, focusing on how to improve work-life balance for employees is a vital part of an organization's success. Today's, if you're an employer, need to understand that employee is stressed at the moment, even if the workplace isn't the cause, but remember that the whole world is very stressful at the moment. This study illustrated about humanity filled with conflicting responsibilities and commitments at work-life balance has become a predominant issue in the workplace. Job satisfaction is an aspect most of labor that measure of utility at work (Bockerman \& Ilmakunnas, 2012). According to (Jamal \& Muhammad, 2012) job satisfaction is an individual's feelings or related views about work and its associated aspects. The key point of an employee practices in organizations is to improve employee productivity and performance to sustain the organization's competitive advantage (Ning, 2012). Hence, the ultimate impact will be on an organization's productivity if workers are not satisfied with their jobs, management, working conditions, or work culture, perhaps they may not provide their customers with quality service (Jamal and Muhammad (2012).

Basically, work-life balance has become an important issue for both either employees and organizations (Madipelli, Veluri-Sarma, \& Chinnappaiah, 2013). This also connected to a business environment that demanding with deadlines and tight schedules (Kumar \& Chakraborty, 2013). The purpose of work-life balance practice is to help reduce work-life conflict and increase positive employee appraisals of the organization (Lazar, Osoian, \& Ratiu, 2010). Whereby the reals of work-life balance can improve organizational structural, cultural, and relational support for work and family (Kossek, Lewis, \& Hammer, 2010). The ranging from economic to environmental emerged, requiring employers to further mainstream work-life initiatives to respond to new societal changes, including from health to technology
(Kossek et al., 2010). Significantly employees are experiencing increasing of the performance pressures, and the hours of employees spent at the workplace (Burke (2010). Furthermore, there is an ongoing struggle between employees and employers concerning work-life balance as they don't understand the reality of work-life balance is reciprocally beneficial (Kumar \& Chakraborty, 2013). Essentially, employers are not responsible for providing work balance for their employees, but they can assist the employees in seeking and maintaining their work balance. Therefore, the decisions, policies, values, and expectations in workplace support employees in their work-life balance choices.

However, looking into an organizational perspective, work-life balance may be a part of good performance, and from an employee perspective worklife balance may be a positive factor in deciding to work for or continue in the same particular organization (Mayerhofer et al., 2011). The success of an organization's employee commitment is an important factor (Shahid \& Azhar, 2013). The importance drivers of employee commitment are employers' care, concern, fairness, and fulfillment (Shahid \& Azhar, 2013). Specifically, the responsibility of every employer is to provide a pleasant work environment and conditions for employees devoid of risks, hazards, and diseases (Howard-Quartey \& Buenar-Puplampu, 2012). Therefore, it's related to facilitate to reduce employee absenteeism, stress, turnover rates, increase employee retention and commitment to the organization (Kumar \& Chakraborty, 2013; Wang \& Walumbwa, 2007). This work-life research also focused on understanding the contributions of work-life balance on employee motivation, job satisfaction, turnover, retention, absenteeism, and productivity an important understanding of the effectiveness of the work-life balance.

Essentially, developing a harmonious worklife balance or work-life integration is critical, though, to improve not only physical, emotional and mental well-being, but it's also important for career. The reality of work-life balance is the state of equilibrium where a person equally prioritizes the demands of one's career and the demands of one's personal life. The consistency of work-life balance has numerous positive effects, including less stress, a lower risk of burnout and a greater sense of well-being. This not only benefits employees, but employers, too. Specifically, those committed to providing environments that support work-life balance for their employees can save on costs, experience fewer cases of absenteeism, and 


\section{SJIF Impact Factor: 7.001| ISI I.F.Value:1.241| Journal DOI: 10.36713/epra2016 ISSN: 2455-7838(Online)}

\section{EPRA International Journal of Research and Development (IJRD)}

- Peer Reviewed Journal

enjoy a more loyal and productive workforce. Therefore, employers that offer options as telecommuting or flexible work schedules can help employees have a better work-life balance. When creating a schedule that works for employees, think about the best way to achieve balance at work and in personal life. According to Chancey said that work-life balance is less about dividing the hours in people's day evenly between work and personal life and, instead, is more about having the flexibility to get things done in professional life while still having time and energy to enjoy personal life.

\section{DESIGNING OF PLANNING STRATEGIC IN WORK-LIFE BALANCE}

Life is a balancing means various factors that safe to say that almost everyone is seeking work-life balance. The meaning of work-life balance has chameleon characteristics that are aiming for different things to different groups, and often depends on the context of the conversation and individual viewpoint. While some number of organizations now are understanding the importance of sustaining a wholesome workforce with acceptable work-life balance. However, it's turning into a frightening process for employers to advertise a wholesome lifestyle, care for the bodily and psychological wellbeing, of the employees whereas doing what it must do, that's will be working the business. The following are working terms used in work-life balance for continuing to evolve.

\section{Flexible working hours}

The phrase work-life, giving a broader worklife connotation or labelling referring to specific areas of support employees to have versatile working hours, particularly working from home that encourage worklife balance strategies for employees. Utmost flexible work is required or not specifying work timings in any respect until the time the work will get carried out. This permits employees to cater to their family wants without compromising on work and digital engagement concepts may assist them to get engaged with work and home life balance.

\section{Educating Employees}

Organizations determine a measurement for specific issues that employees must realize a greater work-life balance. Hence, organizations can play an important function by educating them by way of seminars, webinars, coaching applications, and even estudying. It may develop employee with easy on regular basis structure that they'll use to cut back stress and obtain a higher work-life balance.

\section{Focus on high quality}

Employees have to encourage to work effectively moderately than by counting the variety of hours. Essentially working long hours doesn't result in greater productivity in making work-life balance strategies for employees. On the opposite, an effect on employee morale adversely may cut back the effectiveness and improve stress. Focusing on effectively not solely improves productivity, but additionally ensures the employees that they're trusted to finish their work without fixed supervision and micromanagement their work relationship. It not solely improves their high quality of life, but will increase their productivity and profitability of the group. When a corporation focuses on employee wants, it enhances the employer model, thus, attracting and retaining the most effective expertise. While people must take the duty to find a work-life balance, their organizations can play an enormous functional in attaining work-life balance strategies for employees.

\section{Leave door open}

Mostly all employees are different and will deal with their work-life balance in different ways, therefore it's important that employees feel they can communicate their needs to employer. Make an arrangement to talk with employees, to discuss what can be done to help ease or change the situation and bring their work-life balance to a better place. Through this implementation work-life balance strategies of employees' physical and mental well-being, as well as overall health can improve. Moreover, it can boost their performance at work, by helping people relax, reenergise and improve staff morale. Whilst creating a better work-life balance may not always be easy, it's important to do individual part as a business. Without support, employees can become stressed and unproductive, which can lead to a negative impact on the overall performance in an organization.

\section{Connecting with families}

Essentially employee's family commitment is a piece of the work-life balance that help to increase employee retention and also boost the company's reputation as a respected employer. The scope of benefits that offer employees space to address their personal and family commitments, while at the same time compromising their work responsibilities. The extent to which an organization's culture initiates acknowledges, respects the family responsibilities, encourages management and employees to work together to meet their personal and work needs in reducing employee's stress. Initially employed, who 


\section{EPRA International Journal of Research and Development (IJRD)}

fail to make time for self-care, eventually damages their output and productivity.

\section{Encourage creativity \\ Psychological health, encouraging necessary physical health with work-life balance strategies for employees. Allowing employees to take up inventive tasks or giving them alternatives to current new concepts, promotes innovation within the group, and makes the employees really feel that their concepts are valued. It provides them a break from their daily transactional work and will increase employee satisfaction. Employees able to achieve work-life balance by motivating, gratifying and stay happy employees, whose needs work balancing are achieved that lead to develop stay with their employer and more productive.}

\section{DESIGNING GOAL AND TARGET METHOD}

A healthier work-life balance would allow people the opportunity of spending time with family and friends, giving them change of engaging in hobbies and essentially enjoy life more. This boost in employee happiness is directly reflected in the success of the business, with both employees and employers gaining massive benefits including below list:

i. Helping to avoid employee burnout and overworked, giving them more energy and focus when they are at work.

ii. Improving employee health by reducing the stress and pressure they feel from having to juggle work and home-life and giving them more time to relax and look after themselves.

iii. A reduction in employee absenteeism is often seen as employees are more likely to go to work if they feel a healthy balance in their life and are less likely to take time off sick.

iv. Improving staff retention by ensuring employees are happier in their working environment. This, in turn, reduces the time spent training new staff, increases the amount of in-house expertise and boosts loyalty from staff.

v. Increasing productivity of workers, as productivity is often increased when employees enjoy their role and have less stress in their life.

vi. Better relationships between employees and management, as employees feel appreciated and believe management is putting the needs of the employees ahead of the needs of the business.

vii. Employees are less stressed, less pre-occupied and more able to focus on work, leaving home issues at home and work issues at work.

viii. Organization becomes more attractive to work for as it becomes known as the organization that cares for its employees, which is particularly useful when advertising new roles in the company.

\section{IMPLEMENTATION OF THE EMPLOYEE'S WORK LIFE BALANCE METHOD}

1. Design of Hypothesis Method

i. Increase awareness of leaders, managers and supervisors

ii. Build a supportive work culture

iii. Setting employee expectations

iv. Flexible working hours

v. Telecommuting

vi. Lead by example

vii. Encourage physical activities

viii. Encourage creativity

ix. Connecting with families

x. Identifying burnout

xi. Automating processes

xii. Focus on quality and not quantity

xiii. Different ways organizations manage flexible time

xiv. Difficulties with implementing flexible time in teams and work groups

xv. The absence of communication and education about these policies

xvi. The possible stigma or career penalties associated with using flexible time.

\section{Analyse and interpret data or information}

Despite the fact that the debate around work life balance is not new, it is becoming important as more people in the workforce are struggling with it. The entire factors contribute to an over work stress and leave little or no time for family, friends, physical activities or hobbies, that's causing work life imbalance.

i. Most organizations usually have fixed policies that may or may not suit for individuals, perhaps it gives little or no control over their lives and leaves them struggling on a day to day basis.

ii. The pandemic work from home situation has resulted even more stress on the 
employees, adding much more imbalance to the work life situation.

iii. Technology has made employees accessible to work, around the clock and seven days a week.

iv. Fear of losing their job or losing a promotion further incentive working for longer hours.

v. Addiction to gadgets does not allow people to unplug and switch off. A real challenge that makes employee constantly glued to their gadgets and check their messages and e-mails, constantly, even beyond working hours.

vi. Rising use of social media not only wastes a lot of time, but also causes dissatisfaction as people increasingly seek perfection, looking at the lives of other people.

vii. People are getting more ambitious and competitive, therefore employee not only looking at materialistic incentives, but also seeking higher acknowledgement and appreciation at workplace and want to climb the corporate ladder at a faster pace.

viii. Due to the increasing work demands, people let go of some important components of a healthy life like eating healthy, sleeping well and exercising with added work stress, reduces the resistance of the body and leads to mental clutter.

\section{KEY STRATEGIES IN ACHIEVING A WORK-LIFE BALANCE}

There are many challenges to obtaining a healthy work-life balance yet, a simple action to consider moving closer to the balance desire. The outlined in below strategies are designed to help people restore the balance and harmony in work and personal lives.

\section{Determine Priorities}

Defining and prioritizing what's most important to the employee at this present moment will make all the difference when looking at work-life balance as one of the priorities. In-fact it's challenging to do everything on to-do list with limited time and energy, so need to determine what is priorities are focused and reflected on the wheel to improvements or changes need to make to bring about work life balance.

\section{Set Specific Goals}

Take the list of priorities and turn into concrete and measurable goals, this may ensure that employee no longer lets the work-life balance and other responsibilities get in the way that need to be driven by goals. Life is an evaluation questionnaire grading the key areas, and reflecting on scores into a doable goalsetting format.

\section{Structure Week}

Achieving work-life balance means we need to begin focusing on what is important to us already have it all, but probably not all at once. What should I aim for? Use this question when planning and create to do list which undoubtedly will be very work orientated. In an ideal person with great work-life balance would include the following in their day also week schedule and this list will be easier for on tract self-created deadlines:

i. An 8 hours maximum working day and 8 hours of sleep at night.

ii. Time for breakfast, lunch, a balanced healthy diet and travelling to work in the morning.

iii. No work on weekends.

iv. Quality time with their partner, children and for self.

v. An hour of exercise every day.

vi. Social activities at least twice a week.

vii. Regular contact with family and friends.

viii. Time in nature.

\section{Establish Boundaries}

Set fair and realistic limits on what will and will not do both at work and at home. Clearly communicate these boundaries to supervisor, coworkers, partner and family. Consistently maintain the boundaries according to availability workout.

\section{Leave work at work and respect private time}

Work is work, home is home, there should be no place for work at home (unless, of course, the nature of the job work from home) perhaps limit bringing work home. Develop a mental on-off switch between work and home helps to establish a transitional activity between the two realms.

\section{Get control of thoughts}

Thoughts can be best friends and worst enemies in other words, thoughts in people's heads constantly popping into minds can be either positive or negative. Thoughts drive emotions, which drive behaviours, and ultimately determine the actions thus, a positive emotion can decrease stress hormones and build emotional strength.

\section{Take Personal Responsibility}

Proceed with personal responsibility for worklife balance includes speaking up about work expectations and demands are too much. Be more 


\section{EPRA International Journal of Research and Development (IJRD)}

effective in responding to change in a way that moves forward for every decision making.

\section{Aim for satisfaction}

In realism people are deeply dissatisfied personally and professionally. Life's satisfaction has been defined as an individual's perception of the quality of his or her life as a whole or within specific life domains so it is clear, with experience satisfaction to work on each key area of life to bring about improvement. Concentrating on each has gone to bring satisfaction even before managed to reach the right balance and every bit of improvement will add to satisfaction. An important part of personal development is the concept of continuous improvement and are truly committed to a philosophy of continuous improvement, because people are always in search of the next goal.

\section{Total life planning}

Total life planning is a new advanced innovative approach in developing work-life benefits and helps employees examine important aspects of their professional and personal lives and understand how they relate. Their goal is to encourage how to look at their lives as a whole assess relationships, emotional, physical well-being, careers, spirituality, and their personal financial situation. Ultimately, employees can assess their available choices to improve balance in their lives and develop an individualized life plan. The successful technical set a goal-oriented environment with a meaningful and transformational component for each individual (Traynor, J. B. (1999). The concept of total life planning represents a paradigm shift in society, thus, one of the major benefits is renewed employee energy, enthusiasm for work, and increased productivity. Total life planning obtainable benefits such as health, life, and disability insurance, or on a standalone basis.

\section{WORK-LIFE BALANCE MEASUREMENT}

\section{Key Communication}

In this study also illustrated the work-life balancing is about communication, although an organization offers a rich menu of work-life benefits, the desired effect yielding positive business results are unlikely to occur if employees do not understand the working strategy as stated in below critical questions:

i. does the organization culture truly support work-life benefits;

ii. does the management philosophy, starting with senior management, sincerely endorse work-life benefits; iii. managers and supervisors to understand the impact work-life balance has on their workforce;

iv. are employees aware of and do they understand the organization's work-life balancing?

Eventually, employees will see how these benefits offer the ways to manage work-family conflict if an organization already offers work-life benefits, the next step will be to repackage and re-communicate. In addition, developing a human resource strategy that is clearly integrated with the organization's mission will demonstrate how committed the organization is to employee needs. The following are suggestions to promote work-life balance:

- Review the human resources strategy to see if it supports the employee's mission.

- Through focus groups, find out what employees feel about work-life balance.

- Align work-life initiatives with Human Resources strategy (e.g., employee of choice).

- Create a work-life award program using noncash incentives aligned employee's objectives

The illustration of work-life balance denotes to an individual's ability to maintain a healthy balance between their work roles, their personal responsibilities, and family life. Meaning by accepting the facts that live life to full content will require some sort of balancing between personal and work life. Depending how employee taken into concentration either a positive way than the work-life balance can be achieved to a greater extent.

\section{Constructing Work-Life Strategy}

This study also explains the importance of responsibility for employees' balance. The success of any work-life initiative starts with each player on the team playing his/her part. Executives and leaders need to articulate a vision for a healthy and resilient work force, a productive, successful organization, and satisfied employees. Ultimately, managers need to model healthy habits and balance behaviours, such as good self-management (time, stress, and career management, healthy lifestyle choices, conflict resolution, and problem solving). In this case employees also need to take responsibility for their own choices (diet, exercise, sleep, stress reactions, relationships, career development, and personal and professional development). The following step process can be used for assessing the current situation and appropriate strategy in work-life balancing development: 
i. Assess current position review existing programs, policies and pilots if appropriate benchmark against other organizations. A good indicator of where to focus energies is finding the discrepancy between what employees across the organization think is available.

ii. Articulate employee's plan, set goals, document objectives, and complete an action plan. Probably organization took decades to develop the behaviours and attitudes that are contributing to employee imbalance, employees have likely developed their unhealthy habits over the years. Build on quick wins to figure the momentum before tackles the big issues like changing organizational culture. Be realistic in achieving work-life balance is hard, not impossible, but it requires effort, collaboration, and cooperation.

iii. Execute the plan, establish monitoring and reporting procedures and routines, ensure accountability, provide adequate resources, and communicate continuously. Measure everything so employee know what to

\section{The Tool Box}

celebrate, modify, or stop doing some things.

The use of work-life continuum as a tool for developing, implementing, and monitoring employee organization's plans. The value of the tool is the ability to identify what elements employee have at each stage and to leverage those who are ahead to pull the rest along. To achieve that goal employee will need to position initiatives as a competitive imperative for organizational success and as a strategic business issue, so will link work-life balance initiatives to enrolment and retention strategies, business development goals, and organizational development initiatives. Also, it explores the full life cycle and includes all personal responsibilities, such as education and career development and caring for aging relatives or ill, injured, or disabled family members. The employee may establish a multidisciplinary task force to monitor and expand existing policies and to evaluate progress to benchmark employee progress and learn from other organizations' experience. In addition, may develop metrics and measurements to hold individuals and managers accountable for creating supportive work environments, such as including work-life balance and wellness in measurement tools. The business case for work-life balance practices relies on their ability to enhance recruitment, retention, and reduce work-life balance conflict among employees. Thus, its inbuilt sense that offering work-life balance practices would attract individuals to an organization, and that using these practices would result in improved employee attitudes and behaviors within the organization. However, two things become clear after reviewing this study, illustrated with work-life balance practices and organizational performance.

\section{EVALUATION OF WORK-LIFE BALANCE IN ORGANIZATION}

Essentially the main key addressing the concern of losing control is to educate and skill managers to manage performance and flexibility within their work teams. Specific identifies actions that organizations can take to address this issue is that the managerial skills that create organizational effectiveness are the same skills critical to managing a diverse and flexible workforce as skills elaborate include:

i. The ability to define and agree the work to be done and the standards that need to be achieved.

ii. Implementing systems and processes that allow the employee to work effectively and productively whether that is from the corporate office or another location.

iii. Communicating explicitly about standards for quality and on-time delivery.

iv. Creating an environment where employees communicate their concerns and creative ideas.

v. Evaluating and monitoring progress, and being able to modify systems where needed.

vi. Providing regular feedback and coaching on performance.

vii. Promotes work-life flexibility options for all staff by using examples and case studies as part of in-house promotional materials to show the success stories at all levels of the organizations.

viii. Demonstrate a willingness to explore ways in which senior roles can be re-designed to accommodate greater flexibility in where and when work is done.

ix. Concentration on outcomes rather than time spent in the office. Shift rational thoughtful away from thinking that presence equals professionalism and performance.

x. Establish a formal process for requesting a flexible work arrangement that is monitored by the Human Resource or Diversity 
Manager. Emphasize that all staff has an equal opportunity to have their needs reviewed fairly and objectively.

xi. Apart from their regular performance discussions, ask the question what can I do to support on achieving work-life balance, what barriers need to be removed or challenged? Ensure that they take action on the requests.

xii. Help executives assess low value work and review workloads and work practices so that that reduces the amount of time they have to spend on non-essential work, or work which can be delegated to others.

xiii. Embrace questions about work-life issues and access to senior roles as part of the regular employee consultation/survey process. Take action on the findings.

\section{IMPLICATION AND DEVELOPMENT STRATEGY IN ORGANIZATION}

1. Organization to facilitate education programs that up-skill to manage work-life flexibility issues within their teams include below information:

i. The business benefits of work/life options and flexible working.

ii. Managing the performance and output of employees who work flexibly. This should also include management of poor performance (sometimes this is blamed on the flexible work arrangement and avoids dealing with the real issues of performance.)

iii. Building trust between the employee and manager.

iv. Establishing clear communication channels between the manager, employee and team members so as to avoid crisis situations and resentment between team members. This kind of training needs to be practical and include case studies and skill development exercise.

2. Provide one-on-one coaching for managers as they respond to requests for flexible working done by either a senior manager or a member of the Human Resource team. They can work with the manager to ensure that below scope linearity:

i. Clear performance indicators are discussed and established as part of the flexible work arrangement.

ii. The days, times, location and work hours of any arrangement are clearly established particularly important where an employee is working from home.

iii. Both parties agree what success will look like and how it will be measured.

iv. How communications between the employee/manager/client/customer and colleagues will be managed.

v. Dates and times are agreed when the manager and employee will meet to discuss the effectiveness of the flexible work arrangement.

3. Defined clear procedures for flexible work arrangements. The procedures should illustrate which options are available, which may access them and the criteria that will be used to assess an employee's application to work-life balance flexibility. This method will provide a level of playing field for all employees, which give guidance to managers who may be reluctant to relinquish control by allowing employees to work flexibly.

4. Communicate success experience stories within organizations is best practice that suggest sharing hence, helps managers to recognize that change is possible. Whereby, bottom line the benefits in an organization that's being gained from trusting employees and being proactive in the way they manage work-life balance flexibility issues within their teams.

\section{IMPROVEMENT THROUGH THERAPY IN WORK-LIFE BALANCE}

This study enlightens recognize a separation between a job and living a fulfilling life is essential to improving one's wellbeing both physically and mentally. Basically, Work-life balance is not something everyone can accomplish and often requires something significant to alter their mindset and perception of what is important. Psychologists are able to work with people to recognize how it is important to live a life that includes time for family, friends, work, exercise, leisure, and adequate sleep. Mostly, those who lack of work-life balance often brings work home, struggle with insomnia, cancel plans because of their other obligations, and tend to have a short temper. Strengthening the majority of energy to work can also cause people to suffer from severe tension headaches, upset stomachs, and an increase of caffeine and alcohol use. Subsequently, articulate on employers that realise the work-life imbalance is not in their commercial interest, as it causes absenteeism, poor punctuality, reduced creativity and commitment, and low performance and productivity. Specifically, some of 


\section{SJIF Impact Factor: 7.001| ISI I.F.Value:1.241| Journal DOI: 10.36713/epra2016 \\ ISSN: 2455-7838(Online) \\ EPRA International Journal of Research and Development (IJRD) \\ - Peer Reviewed Journal}

employer design the work schedules that cater to their employees' actual, varying needs. Thus, management knows that staff who take 'productivity pauses' return to the task at hand with renewed vigour and focus. They obtained a good example by going home at a sensible hour to spend time with their family and friends. Despite this challenging socio-economic context, therapy is able to help manage the actions and reactions, regulate self-efficiency, self-integrity and feel that self in control of life and the abilities to 'steer your own ship'. The consequence of Therapy for a better work-life balance can be learned depending how the understanding takes place in balancing work-life improvement:

i. 'Stall constructive' when asked to do something extra

ii. Work 'smart not long', by means of tight prioritising.

iii. Become more willing to delegate.

iv. Differentiate 'good enough' from 'fabulous'.

v. End the workday without completing every work task and yet feeling satisfied

vi. Includes downtime the schedule.

vii. Make a little time for the things that ignite the joy.

viii. Think about other interests, outside of work, that will need to have when get older and maybe retired.

ix. Set manageable goals each day and create a "To Do" list to stay on task.

x. Be efficient with the time at work and don't procrastinate or get preoccupied with spending too much time doing busy work.

xi. Ask for flexibility in scheduling. It allows for increased productivity.

xii. Take small breaks throughout the day to clear the mind and reduce stress.

xiii. Tune in, studies show that listening to music at work fosters concentration, reduces stress and anxiety, and stimulates creativity.

xiv. Communicate effectively and be honest when someone can help or when a project or task becomes overwhelming.

xv. Give self a break, no one is perfect and all people can do is their best.

xvi. Unplug, the same technology that makes it so easy for workers to do their jobs flexibly can also cause burnout when used all of the time.

xvii. Divide responsibilities at home and evenly distribute tasks to avoid getting behind.

xviii. Learn to say "NO" when feeling stressed or exhausted. xix. Make time for friends and family to create a strong support system when life spirals out of control.

xx. Stay active and treat the body right, do regular exercise, adequate sleep, and a healthy diet boosts the immune system and are proven to reduce stress, symptoms of depression, and anxiety.

\section{CONCLUSION}

Overall, this study shows that work-life balance practice is most effective when they enhance employees' autonomy and increase their capacity to perform well at work and in a family situation. The convergence between work and non-work aspects a win-win situation for employees and employers alike. The capability to achieve satisfying experiences in all life domains enhances the quality of personal relationships and a range of organizational outcomes. The readiness of the work-life balance practices, provided in the context of organizational support that can reduce work-life conflict and increase positive appraisals of one's organization. It is also associated with employee attitudes such as increased job satisfaction and enhanced control over their work schedule. In fact, a significant improvement notice in an employee's work-life balance mainly relates to morale, reduce absenteeism, and retain organizational knowledge, especially during in difficult economic times. Globally, current situation marketplace, as organizational key objective is to reduce costs, which falls to the human resource professional to understand the critical issues of work-life balance. It's illustrated in this study that eemployees will feel a greater sense of control and ownership over their own lives, they tend to have better relationships with management and just let work issues at work and home issues at home. In the circumstance balanced out employees tend to feel more motivated and less stressed out at work, whereby increases organizational productivity and reduces the number of conflicts among co-workers and management. Today's organization take opportunity in gaining the reputation to encourage work-life balance to become more attractive among employees and will draw a valuable pool of candidates for new job openings. The organization will convey to enjoy higher employee retention rates, which results in less time-consuming training, more loyalty, and a higher degree of in-house expertise. Nevertheless, this study also determines employees who have a positive work-life balance do a better job at work, so promoting this balancing as beneficial to individuals and the organization. This will 


\section{EPRA International Journal of Research and Development (IJRD)

be a practical guide for employers who want to promote a healthy work-life balance for their teams.

\section{REFERENCES}

1. Bockerman, P., \& Ilmakunnas, P. (2012). The jobs satisfaction-productivity nexus: A study using matched survey and register data. Industrial \& Labor Relations Review, 65, 244-262.

2. Chimote, N., \& Srivastava, V. N. (2013). Work-life balance benefits: From the perspective of organizations and employees. IUP Journal of Management Research, 12(1), 62-73.

3. Howard-Quartey, S., \& Buenar-Puplampu, B. (2012). Employee health and safety practices: An exploratory and comparative study of the shipping and manufacturing industries in Ghana. International Journal of Business \& Management, 7, 81-95.

4. Jamal, U., \& Muhammad, S. (2012). Job satisfaction of bank employees working with echannel service delivery network: A study on selected private commercial banks in Bangladesh. Studies in Business \& Economics, 7(3), 165-178.

5. Jang, J. S., Park, R., \& Zippay, A. (2011). The interaction effects of scheduling control and worklife balance programs on job satisfaction and mental health. International Journal of Social Welfare, 20, 135-143.

6. Kumar, H., \& Chakraborty, S. (2013). Work life balance (WLB): A key to organizational efficacy. Aweshkar Research Journal, 15(1), 62-70.
7. Kossek, E. E., Lewis, S., \& Hammer, B. L. (2010). Work-life initiatives and organizational change: Overcoming mixed messages to move from the margin to the mainstream. Human Relations, 63(1), 3-19.

8. Lazar, I., Osoian, C., \& Ratiu, P. (2010). The role of work-life balance practices in order to improve organizational performance. European Research Studies, 13(1), $201-213$.

9. Madipelli, S., Veluri-Sarma, V. S., \& Chinnappaiah, Y. Y. (2013). Factors causing work life imbalance among working women - A study on schoolteachers. Indian Journal of Industrial Relations, 48, 621-633.

10. Mayerhofer, H., Schmidt, A., Hartmann, L., \& Bendl, R. (2011). Recognising diversity in managing work life issues of flexpatriates. Equality, Diversity and Inclusion: An International Journal, 30, 589-609.

11. Ning, H. (2012). How to maintain sustainable competitive advantages-case study on the evolution of organizational strategic management. International Journal of 282 Business Administration, 5, 45-51.

12. Shahid, A., \& Azhar, S. M. (2013). Gaining employee commitment: Linking to organizational effectiveness. Journal of Management Research, 5(1), 250-268.

13. Traynor, J. B. (1999). A new frontier in work-life benefits. Employee Benefits Journal, 24, 4, 29-32. 